\section{RMD Open}

Rheumatic \&

Musculoskeletal Diseases

To cite: Roux C, Cortet B, Bousson V, et al. Vertebroplasty for osteoporotic vertebral fracture. RMD Open 2021;7:e001655. doi:10.1136/ rmdopen-2021-001655

Received 4 March 2021 Accepted 11 June 2021
Check for updates

(C) Author(s) (or their employer(s)) 2021. Re-use permitted under CC BY-NC. No commercial re-use. See rights and permissions. Published by BMJ.

${ }^{1}$ INSERM U1153, APHP.CentreUniversité de Paris, Service de Rhumatologie, Hôpital Cochin, Paris, France

${ }^{2}$ Department of Rheumatology, ULR 4490, Université de Lille, Lille University Hospital, Lille, France

${ }^{3}$ Service de Radiologie 0stéoArticulaire, APHP.Nord-Université de Paris, Hôpital Lariboisière, Paris, France

${ }^{4}$ Service de Rhumatologie, and INSERM U 1059, Université de Lyon-Université Jean Monnet, CHU de St-Etienne, Saint-

Etienne, France

Correspondence to

Dr Christian Roux;

christian.roux@aphp.fr

\title{
Vertebroplasty for osteoporotic vertebral fracture
}

\section{Christian Roux (1), ${ }^{1}$ Bernard Cortet, ${ }^{2}$ Valérie Bousson, ${ }^{3}$ Thierry Thomas ${ }^{4}$}

\section{ABSTRACT}

Appropriate care of patients with a recent painful osteoporotic vertebral fracture (VF) requires immobilisation, analgesics and spinal orthoses. Some VFs are however responsible for disabling pain and prolonged bed rest. In this context, vertebroplasty techniques have been proposed with a large benefit in case series and open-label randomised studies, but lack efficacy in three among four double-blind randomised studies. The objectives of the treatment of a recent painful VF are to relieve pain and to preserve mechanical conditions. With this in mind, we report an experts' opinion paper on the indications for vertebroplasty and research agenda for clinical studies.

Vertebral fractures (VFs), the hallmark of osteoporosis, are associated with several complications; they increase the risk of mortality in the elderly and this increase is related to the number of VFs as well as the severe VF-induced thoracic hyperkyphosis; and they cause loss of body height and deformations of the spine with sagittal imbalance, which are responsible for chronic pain, reduction in respiratory function, increased risk of falling and long-term degradation of quality of life. ${ }^{1}$ VFs are further characterised by their evolution with a progressive decrease in vertebral body height. The occurrence of VFs in the elderly is worrying as it causes acute pain, requiring confinement to bed and prolonged functional disability, with a high risk of deconditioning and pulmonary infections. Treating pain requires immobilisation and analgesics, sometimes including morphine derivatives which could have adverse effects in frail elderly people, a population in whom failure of conservative treatment is more often observed. ${ }^{2}$ Contention with spinal orthoses can help to improve pain ${ }^{3}$ and upright posture, although it is not always easy to use, especially when the fractures are at the thoracic spine. Moreover, there is no evidence on the differences in analgesic effects of the different types of spinal orthoses, from rigid to soft spinal orthoses.

\section{Key messages}

Vertebral fractures can be responsible for disabling pain and prolonged bed rest.

- Analgesics and bracing do not always alleviate pain.

- Uncontrolled and controlled studies show that vertebroplasty is effective in patients with intractable pain.

- Three among four double-blind randomised studies do not confirm this benefit.

- In all cases, a rapid initiation of antiosteoporotic treatment is mandatory.

It is in this context of the need to reduce severe pain and combat prolonged bed rest that in the 1990s the use vertebroplasty techniques was proposed. A huge number of publications, clinical cases, series, and retrospective and prospective analyses of the analgesic efficacy of vertebroplasty were then published and the procedure has been widely adopted. $^{45}$

However, since 2009, four randomised controlled versus sham procedure studies have been published in peer-reviewed journals, and three of four showed no better analgesic and functional benefit response to vertebroplasty compared with sham procedures. A Cochrane review on vertebroplasty concluded that there was overall a lack of efficacy, and no subgroups with specific significant results were identified. ${ }^{6}$ Thus, the American Society for Bone and Mineral Research (ASBMR) Task Force in 2019 issued negative opinions on the continuation of this procedure. ${ }^{7}$ In the mean time, a decrease in the number of vertebroplasties performed has been reported. ${ }^{8}$ In the US Medicare population, vertebral augmentation procedures peaked at $24 \%$ of the patients having $\mathrm{VF}$ in 2007-2008 in the database and then declined to $14 \%$ in $2014 .^{9}$

With this in mind, we have to consider that the appropriate care of patients with a recent painful osteoporotic VF is currently not well defined, with a large variety of management 
among medical centres, uncertainties on the different approaches used and unmet needs paradoxical with the high frequency of this clinical situation.

From a clinical end point, the objectives of the treatment are similar to the ones for non-VFs: relieving pain and preserving mechanical conditions. Therefore, our position paper reconsiders studies on vertebroplasty on a clinical basis and scrutinises the different arguments that may still lead to potential indications of this treatment.

\section{THE VERTEBROPLASTY PROCEDURE}

The technique is performed in a surgery or an interventional radiology room by radiologists, orthopaedic or neurosurgeons, or rheumatologists. ${ }^{10}$ The patient is in prone position. After local anaesthesia (associated or not to conscious sedation) and under imaging guidance, the skin is incised, allowing the passage of a trocar to the vertebra, which is approached posteriorly in a transpedicular or parapedicular way (unilaterally or bilaterally). The trocar is placed in the body of the vertebra and the injection is performed under fluoroscopic control, allowing the expansion of the injected product to be constantly monitored. The product is made of polymethylmethacrylate (PMMA), the volume varying from $2 \mathrm{~cm}^{3}$ to $8 \mathrm{~cm}^{3}$, depending on the local conditions. Beyond the effect of PMMA in the stabilisation of the fracture, the destruction of nociceptive fibres during the exothermic reaction produced by polymerisation of PMMA, which contributes to the analgesic effect, has been hypothesised. The recommendation is to inject the volume of PMMA that best fills the body of the vertebra, without causing marked leakage in the discs, foramens, central canal and veins. During the same procedure, several vertebrae can be treated, with general anaesthesia being necessary most often when more than two vertebrae are treated.

Other techniques are possible, and several methods with percutaneous introduction of an implant (associated or not with cement injection) have been proposed. During kyphoplasty a balloon is first placed and then inflated under pressure to create an intracorporeal cavity; the balloon is then deflated and removed before cement is injected into the cavity. It is also possible to introduce stents, or implant, to push back the vertebral plateau, allowing the vertebral body to expand; these tools can be left in place during the secondary injection of cement. We are focusing this paper on vertebroplasty, the most widespread and affordable vertebral augmentation procedure.

\section{PRIMARY OBJECTIVE: RELIEVING PAIN}

Some VFs are responsible for severe and disabling spinal pain which does not resolve spontaneously. This is the context of inclusions in the studies, with the rationale that fracture healing will be associated with pain relief. Indeed, chronic pain can be related to bone events (increased deformation of the fractured vertebral body, incident fractures of adjacent or non-adjacent vertebrae, fracture non-union (ie, non-healing of the fracture)), but can also be related to non-bone events (related to intervertebral discs, ligaments, facet joints or even muscle pain secondary to static disorder, etc). Comprehensive and careful analysis of the causes of pain is mandatory to use vertebroplasty technique appropriately.

\section{Open-label, non-randomised studies}

From the end of the 1980s, a huge number of nonrandomised studies were published suggesting analgesic and functional benefits of vertebroplasty. Systematic reviews and meta-analyses published between 2009 and 2014 supported a positive effect of vertebroplasty. An evidence-based review of the literature including 74 studies (70 case series) between 1980 and 2008 showed that, compared with optimal medical management, vertebroplasty was more effective in pain control; the level of evidence was good within the first 2 weeks and fair within 3 months after intervention. ${ }^{4}$ This rapid benefit was also reported in three controlled, non-randomised studies, although they showed the absence of long-term (ie, more than 6 months) benefit. ${ }^{11}{ }^{12}$ The recentness of the VF varied among studies. One non-controlled study of 115 patients who had undergone 216 procedures, with a mean time from fracture to vertebroplasty of $6 \pm 3$ months, concluded a long-term analgesic effect independent of the length of time between the fracture and the vertebroplasty. ${ }^{13}$ Thus, although these studies showed a rapid analgesic effect of vertebroplasty, the heterogeneity of the populations prevented defining the appropriate patients who could benefit from the procedure. Moreover none of these studies provided information on fracture non-union prior to the procedure, a criterion which can be assessed only by MRI.

\section{Open-label, randomised studies}

Studies which compared pain relief between vertebroplasty and standard medical care showed consistent results in favour of vertebroplasty, at 1 month and up to 6 months. ${ }^{14}$ In the conservative treatments groups, pain relief was slower and lesser than in the vertebroplasty groups. In one open-label, prospective, randomised and controlled trial enrolling 125 patients, there was a significant decrease in pain initially in both groups; at 2 months, the reduction in pain score was $42 \%$ and $25 \%$ in the vertebroplasty and the conservative treatment group, respectively. It was suggested that the lower difference observed between the groups compared with other studies could be related to a higher incidence of new VFs in the vertebroplasty group. ${ }^{15}$

Vertebroplasty was also compared with facet joint injections (anaesthetic and glucocorticoids in the facet joints of the fractured vertebral body) in one randomised study of 206 patients; there was a significant difference in pain relief between the two groups during the first week, in favour of vertebroplasty, but not at 1 and 12 months. ${ }^{16}$

The VERTOS study ${ }^{17}$ was the first randomised, openlabel study including 34 patients, 18 in the vertebroplasty 
group and 16 in the optimal medical treatment group. After 2 weeks, patients treated medically could receive vertebroplasty; this procedure precluded any conclusion on the long-term benefit. The mean scores on the Visual Analogue Scale (VAS) were 7.1 and 7.6 in the vertebroplasty and the control group, respectively, at baseline, 4.7 and 7.1 at day 1 , and 4.9 and 6.4 at 2 weeks. Population size was small; therefore, differences were significant at day 1 , but not at 2 weeks, in part due to the occurrence of new VFs in the adjacent vertebral bodies in two patients who had vertebroplasty.

VERTOS II $^{18}$ was a larger, open-label, prospective, randomised trial of 202 patients with back pain for 6 weeks or less and a VAS score of 5 or more, comparing vertebroplasty with optimal medical management. The non-healing of the fracture was confirmed by the presence of vertebral oedema on MRI, a key issue in the interpretation of the results. The primary outcome was pain relief at 1 month and 1 year as measured by VAS score. The mean volume of cement injected per vertebral body was $4.1 \pm 1.5 \mathrm{~mL}$; vertebroplasty was performed at a mean of 5.6 weeks after onset of symptoms. Vertebroplasty was more effective, with a significant difference between groups in reduction of pain at both time points (mean VAS score difference of 2.6 and 2.0 at 1 month and 1 year, respectively).

Thus, compared with standard medical management, these randomised, open-label studies showed a shortterm benefit of vertebroplasty in pain. When the procedure was indicated based on evidence of non-healing of the fracture (ie, persistent oedema of the vertebral body on MRI), even long-term benefit of pain was reported. ${ }^{18}$ Thus MRI should be mandatory for vertebroplasty indications, and attention must be paid to persistent oedema or presence of a linear intracorporeal cavity containing gas or liquid, indicating a fracture non-union, that is, the absence of fracture healing (figure 1).

Importantly, the results of these open-label, randomised studies have to be interpreted with the potential bias of a placebo effect that is constantly present in all treatments aimed at reducing pain. ${ }^{19}$ Indeed, this real neurobiological phenomenon with potential meaningful effect could be higher in patients benefiting from the complex vertebroplasty ritual than those receiving analgesics and a contention; the first exaggerating their benefit due to the invasive procedure, and the others exaggerating the lack of effect due to their disappointment of being in a control group. ${ }^{19}$

\section{Double-blind, randomised studies}

The results of the four double-blind studies which used a sham procedure are summarised in table $1 .^{20-23}$ One study analysed in a Cochrane review and an ASBMR Task Force paper is a thesis (2015) not yet published. Detailed analyses of these studies have already been published, ${ }^{67}$ with strong discrepancies in the results not only with the open-label studies but also among them, as one study, the VAPOUR study, ${ }^{22}$ concluded in favour of vertebroplasty while the three others demonstrated no benefit of vertebroplasty compared with a control procedure. We focus here on some critical patient characteristics that may lead to these discrepancies between the results and that prescribers must have in mind.

In all studies there was a large difference between the number of contacted patients and the number of randomised patients. One explanation is the significant decrease or relief of pain during the selection process. Then there was a large heterogeneity in the proportion of patients hospitalised during recruitment, which reached $58 \%$ in the VAPOUR study, ${ }^{22}$ in contrast to the VERTOS IV study where all participants were outpatients. ${ }^{23}$ The single study (VAPOUR ${ }^{22}$ ) with a positive result was indeed performed in a majority of inpatients hospitalised for severe pain with a mean pain score as high as 8.9 despite opiate analgesia.

Inclusion criteria required clinical history and imaging findings consistent with the diagnosis of pain related to an acute VF. However MRI was not mandatory in Kallmes et $a l$ s study, ${ }^{21}$ suggesting that for some patients pain may be due to other causes.

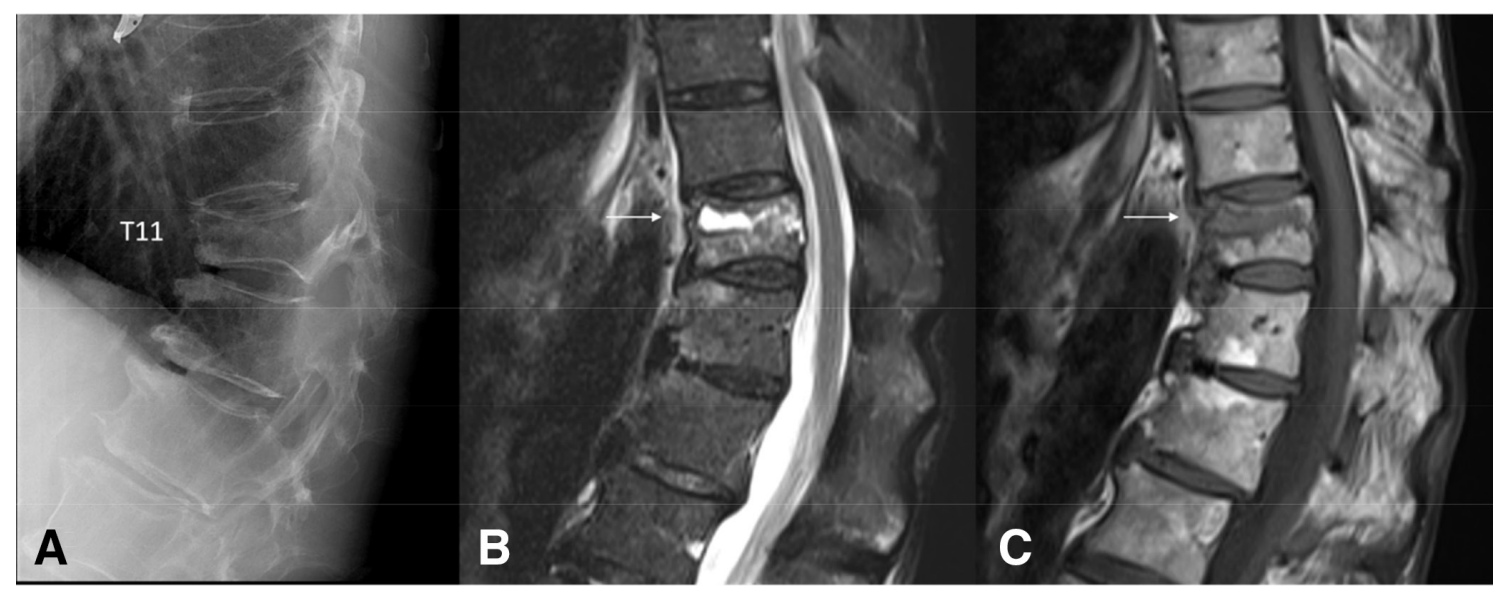

Figure 1 Osteoporotic fracture of T11 in a 78-year-old patient: lateral radiograph (A) and MRI (B,C). Intracorporeal fluid cavity (arrow) on T2-weighted (B) and T1-weighted (C) MRI corresponding to a fracture non-union of the fractured vertebral body. 
Table 1 Data from double-blind randomised studies

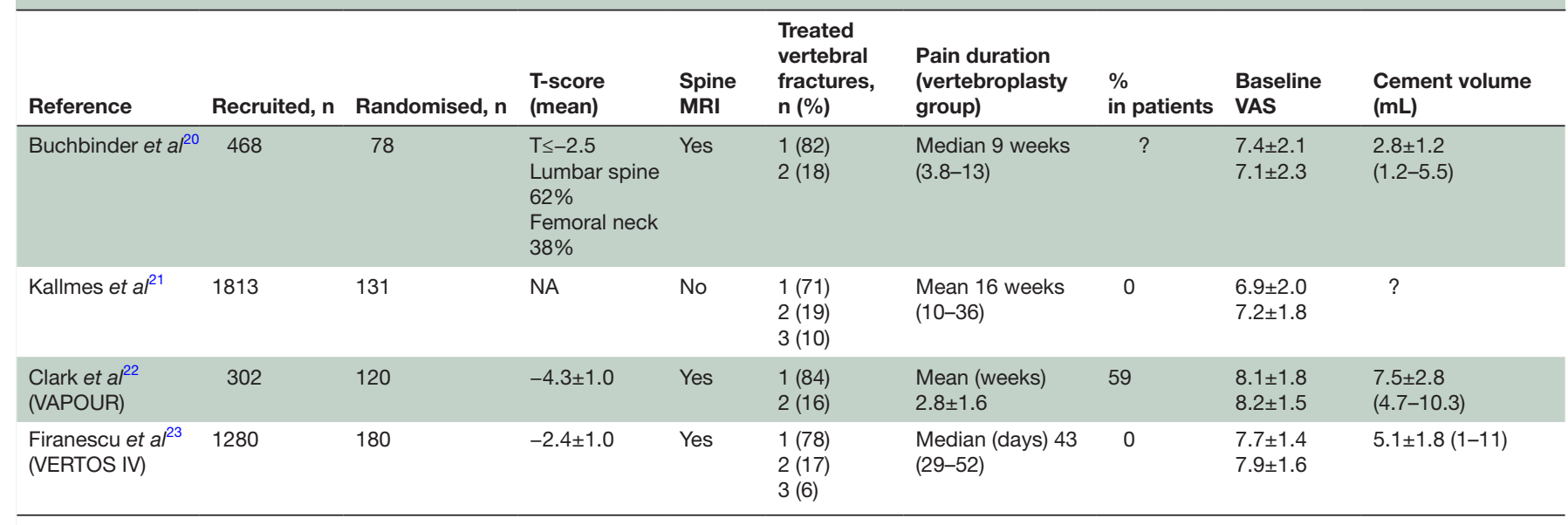

NA, not available; VAS, Visual Analogue Scale.

Time since fracture is an important element of the differences between studies, with a special attention paid to the recent nature of the fracture in VAPOUR and VERTOS IV studies ${ }^{22}{ }^{23}$ whereas pain could have lasted for 1 year in the two others. In VERTOS IV, in which the time of inclusion initially limited to 6 weeks was then extended to 9 weeks, less than $20 \%$ of patients had a fracture for a shorter duration than 3 weeks, compared with $79 \%$ in VAPOUR. ${ }^{24} 25$

The mean volume injected was also different among studies, from $2.8 \pm 1.2 \mathrm{~mL}$ to $7.5 \pm 2.8 \mathrm{~mL}$ (table 1 ). The volume matters, according to an observational study of 106 patients (196 procedures); volume varied from 0.13 $\mathrm{mL}$ to $10.8 \mathrm{~mL}$ (mean $3.9 \pm 41.89$ ) and was smaller in nonresponders than in responders. ${ }^{26}$ However a number of technical conditions, including severity of the vertebral body height loss, hamper the interpretation of this parameter, as the total volume injected could be very low in severe VFs or in non-recent fractures with ongoing healing process.

In these four double-blind randomised studies, the investigators paid careful attention to the sham procedures, a study characteristic which again was not identical among studies. PMMA preparation and operators' discussions were identical in order to make them perceptible to all patients and to keep them blind. No information was given on non-operating investigators, ensuring the same postprocedure care. However, at least one step of the procedure was different: vertebral body was gently tapped, with a stylet in one study ${ }^{20}$ and not in the other ${ }^{21}$; the needle was inserted into the bone in one study ${ }^{20}$ but kept far from the vertebral body in VAPOUR, ${ }^{22}$ although a regular tapping on the needle was performed. In VERTOS IV the needles were positioned in contact with the periosteum of the pedicules bilaterally. Thus, in the sham groups of the three studies with negative results, the needle was placed into the bone or in contact with the periosteum, ${ }^{23}$ in contrast to the VAPOUR study where the needle was not in contact with the vertebral body and thus only a subcutaneous anaesthesia was performed. ${ }^{22}$
A number of clinical situations are not addressed in these studies. Few patients were included with multiple concurrent fractures, precluding conclusions on the benefit of performing more than one vertebroplasty at the same time. In addition, general anaesthesia is requested in such cases, a procedure which was not used in the controlled studies. The indication of such a procedure has to be discussed on a case-by-case basis. Likewise, the benefit to risk ratio of vertebroplasty procedures in patients with a VF cascade, that is, more than three VFs in a short period of time, is unknown. A preventive vertebroplasty in a normal vertebra may be proposed in the complex situation of a 'sandwich vertebra', that is, an uncompressed vertebral body situated between two VFs, a situation at risk of subsequent fracture; however, only limited data from retrospective studies are available in these circumstances. ${ }^{27} 28$

\section{Risk of new fractures}

The risk of new VFs after vertebroplasty is a complex problem as osteoporosis by itself can cause VF cascade; roughly $20 \%$ of postmenopausal women with untreated osteoporosis have a new VF within 1 year after an incident one, and clustering in time of the osteoporotic fractures is well known. ${ }^{29}$ Moreover it is unclear in most of the studies on vertebroplasty if patients received an appropriate antiosteoporotic treatment. VFs of osteoporotic origin should be randomly located along the spine, but a vertebral deformity changes local mechanical conditions, thus changing forces on adjacent vertebral bodies. Careful attention must be paid to discrete oedematous signal in adjacent vertebral bodies at the first evaluation of the patient with a recent VF, suggesting a subtle fracture already occurred in this vertebra.

In VERTOS II study ${ }^{18}$ a randomised controlled trial comparing vertebroplasty with optimal medical management, there was no difference in the incidence of new fractures between the vertebroplasty group and the medical treatment group (18 fractures in 15 of 91 patients and 30 fractures in 21 of 85 patients in the vertebroplasty 
and the conservative treatment group, respectively). Moreover, there was no difference in location distribution of new VFs between the two groups. The only risk factor for a new one was the number of prevalent VFs, which is the natural history of the disease. In VERTOS $\mathrm{IV},{ }^{23}$ a randomised controlled study with sham procedure, there was no difference neither in the incidence nor in the location of incident fractures. In contrast, in a prospective controlled study comparing vertebroplasty and medical treatment, $75 \%$ of the new VFs occurred within 3 months, and $82 \%$ were adjacent to the treated VF (vs $27 \%$ in the conservative group). However, determinants of new $\mathrm{VFs}^{1630}$ were age, glucocorticoid therapy, low vitamin $\mathrm{D}$ and low bone density, which are actually the usual risk factors in this osteoporotic population. ${ }^{15}{ }^{31} \mathrm{~A}$ question on a technical point was raised, that is, whether or not an intradiscal cement leakage is a determinant of risk. In one study ${ }^{15}$ cement leakage into the inferior disc was more frequently observed in patients with new VFs. However, in VERTOS IV, ${ }^{23}{ }^{30}$ cement leakage was demonstrated by CT scans in a large number of cases: $20 \%$ in the disc above, $15 \%$ is the disc below and $10 \%$ in the perivertebral soft tissue. All these leakages were asymptomatic and leakage into the disc above or below was not associated with more incident VFs. Actually, both a metaanalysis in $2015^{32}$ and a Cochrane review ${ }^{6}$ concluded on the absence of statistically significant increase in the risk of both new VFs and adjacent VFs in studies comparing vertebroplasty with placebo or usual care.

\section{Cost-effectiveness}

Mixed results have been reported regarding the costeffectiveness of vertebroplasty. Most of the studies are comparative studies with kyphoplasty ${ }^{33}$ and not versus standard medical treatment. These studies assessed initial costs (instruments, anaesthesia, duration of hospital stay) and medical resource utilisation in the follow-up, including readmissions. In the open-label, randomised trial VERTOS II ${ }^{18}$ the cost-effectiveness ratio for vertebroplasty was within the UK willingness-to-pay threshold. Based on an analysis of Medicare, a Markov simulation model showed that vertebroplasty is a more expensive treatment option than conservative medical management in the short term; however, it is cost-effective at a US willingness-to-pay threshold. ${ }^{34}$

In the current situation in which the benefits of vertebroplasty are debatable and recognising the development of different techniques of vertebral augmentation, more cost-effectiveness studies taking into account underlying socioeconomic factors and assessing both short-term and long-term results are needed.

\section{SECONDARY OBJECTIVE: PRESERVING MECHANICAL CONDITIONS}

A potential severe complication of VFs is disability, related to chronic back pain. A comprehensive assessment of this chronic pain should also take into account

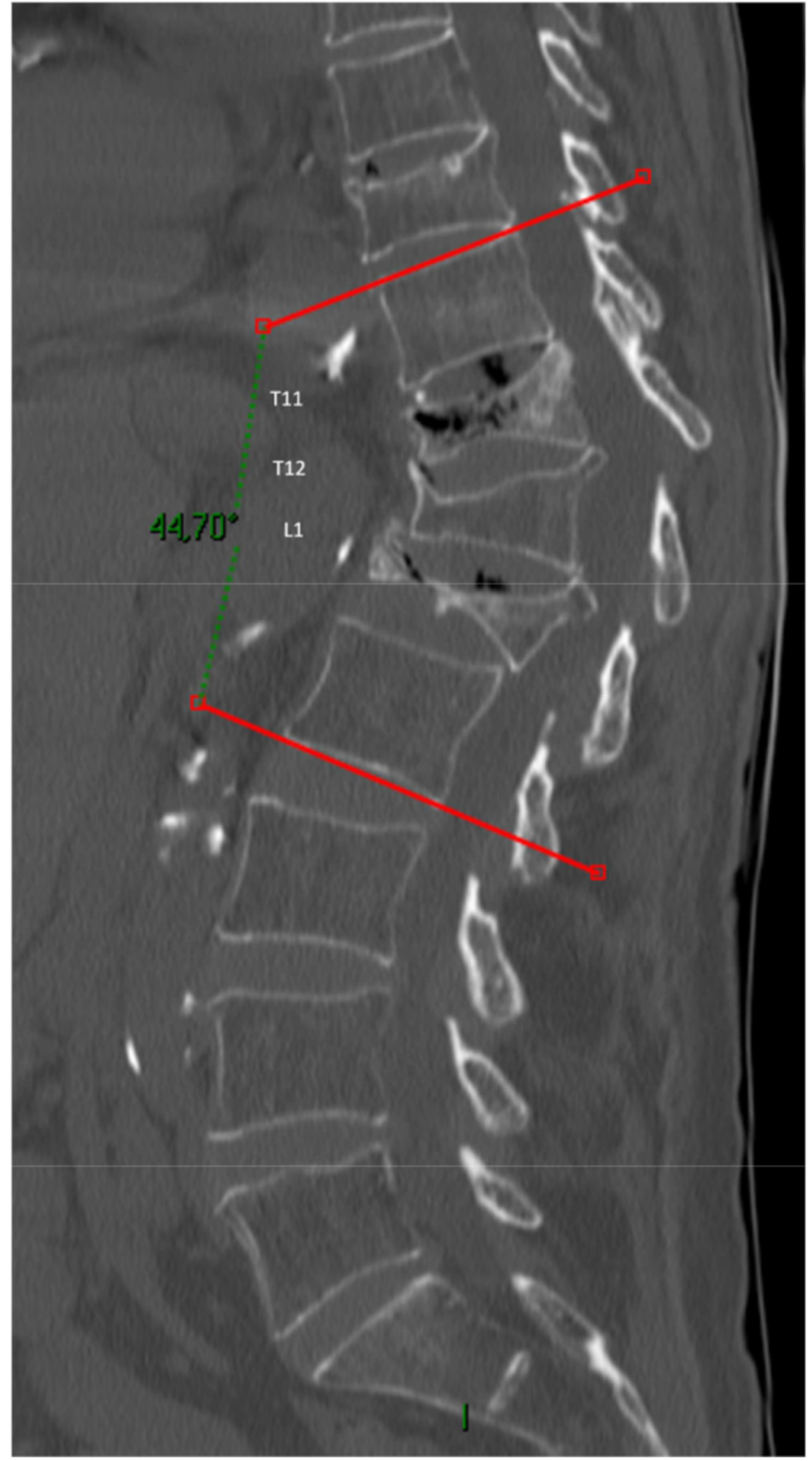

Figure 2 Osteoporotic fractures at the thoracolumbar junction in a 68-year-old patient. Lateral CT scan image showing a regional hyperkyphosis $\left(45^{\circ}\right)$ due to the three fractures. Gas within T11 corresponds to a fracture nonunion.

the global sagittal balance of the spine and the compensatory mechanisms involved in situations of malalignment. This is a frequent situation after VF, in particular at the thoracolumbar level, which is at high risk of fracture due to it being at the junction between the relatively fixed thoracic spine and the mobile lumbar spine. Increase in thoracic kyphosis is also a significant and independent risk factor for incident $\mathrm{VF}^{1}$ Thus, considering the future of the patient and potential worsening of mechanical conditions, one may consider the need for a local treatment for preventing impairment of vertebral statics and spinal sagittal balance (figure 2).

Osteoporotic VFs cause spinal sagittal imbalance and failure in sagittal compensation; actually one VF is 
enough to significantly change the sagittal balance, and the number and severity of the fractures worsen the situation. ${ }^{35}$ In a study of 1044 postmenopausal women with osteoporosis prospectively followed over 5 years, patients with VFs had unfavourable changes in lumbar lordosis, sacral slope and pelvic incidence. ${ }^{36}$

Sagittal spinal balance can in turn have an influence on the symptoms and the prognosis of VFs, the occurrence of new VFs and their location. In a prospective study conducted over 2 years in 240 patients with painful VFs, the risk of adjacent fractures was higher in patients with altered spinopelvic balance parameters; the risk decreased if the segmental kyphotic angle was less than $11^{\circ} .{ }^{37}$ A greater sagittal vertebral axis, used to determine sagittal global balance on whole spine radiographs, was suggested to be a risk factor for delayed union of osteoporotic VFs. ${ }^{38}$ The spinal malalignment may increase the load sharing at the fracture site and may interfere with the fracture healing. In a cross-sectional study conducted in 79 patients $^{39}$ (mean age of 73 years), patients with optimal spinopelvic parameters and sagittal alignment were more likely to respond to medical treatment of VFs and not to surgery.

These results suggest that assessment of parameters such as the sagittal vertebral axis, pelvic incidence and pelvic tilt could help to predict long-term outcomes defining patients with optimal possibility of compensatory mechanisms. No study has been conducted using these parameters as predictors of the clinical benefit of vertebroplasty. However, based on these hypotheses, spinal sagittal balance and height loss of the fractured vertebrae should also be assessed as a relevant outcome of vertebroplasty. In contrast to treatment of non-VF by surgery, restoration of normal anatomy cannot easily be reached for fractured vertebral body. During the vertebroplasty procedure, patients are placed in a hyperlordosis position, with a potential slight vertebral body height increase. However the gain in vertebral body height has no significant local effect, that is, on regional kyphosis angle. Thus the question is not to restore local normal anatomy but rather to prevent worsening of vertebral height loss. In VERTOS II, further height loss of the fractured vertebrae was observed in $8 \%$ and $45 \%$ of patients in the vertebroplasty and the control group, respectively. ${ }^{18}$ After conservative therapy, further height loss of the fractured vertebrae occurred more frequently, and grading was more severe than after vertebroplasty in VERTOS II. In VAPOUR, the fracture height loss was $27 \% \pm 12 \%$ and $63 \% \pm 17 \%$ in the treated and the placebo group, respectively. ${ }^{22}$ In the long-term 12-month follow-up of VERTOS IV, further height loss of the treated vertebrae occurred more frequently in the sham procedure group than in the vertebroplasty group (39 patients (45\%) vs 7 patients $(8 \%)$; $\mathrm{p}<0.001, \mathrm{OR}=9.84$, $95 \%$ CI 4.08 to 23.73$)$ and was more severe $(p<0.001){ }^{30}$ A further step was suggested by a German working group who published recommendations based on a score to evaluate an individual's indication for interventional treatment, including vertebroplasty, with or without short segment percutaneous instrumentation. ${ }^{41}$

These data suggest that spinal sagittal balance and its compensatory mechanisms resulting from patient anatomy and VFs should be assessed to orientate patients with an acute VF towards a vertebral augmentation procedure or medical treatment. There is an urgent need for studies of appropriate methodology to assess the shortterm and long-term benefits and harms of such interventional management.

\section{POTENTIAL OBJECTIVE: DECREASING MORTALITY}

Given the potential effects of vertebroplasty in improving mobility and preventing reduced pulmonary function, it is legitimate to assess its effect on mortality. The Medicare database was used to study the 4-year outcome of 858978 patients with VFs, of whom 63693 had vertebroplasty and 119253 had kyphoplasty. ${ }^{42}$ Patients who underwent one of these procedures had a $37 \%$ reduction in mortality risk compared with non-operated patients. The second study ${ }^{43}$ compared 524 patients who had vertebroplasty with 589 fractured subjects from a historical cohort and found no difference in mortality rate between the two groups. Actually a subgroup analysis of this study showed a higher mortality rate in the group of vertebroplasty patients compared with the group of patients with asymptomatic VF. Another retrospective study did not show any effect on mortality. ${ }^{44}$ In these studies, patients treated with vertebroplasty were with no doubt different from others, limiting the evidence despite various adjustments. Using propensity scores, Ong et at $t^{45}$ reported a $4 \%$ higher propensity-adjusted mortality risk for patients with VF which occurred in the 2010-2014 vs 2005-2009 periods, in parallel with the decreased use of vertebroplasty for osteoporotic VF. A recent meta-analysis including seven studies (and data on more than twomillion patients) showed that HRs for mortality benefit of vertebral augmentation versus conservative management across 2-year and 5-year periods were $0.70(\mathrm{p}<0.001)$ and 0.79 $(p<0.005)$, respectively. ${ }^{46}$ There is however a high heterogeneity between studies included in this meta-analysis $\left(I^{2}=88 \%\right)$. These observational studies are also likely confounded by indication. Thus so far no solid conclusion can be drawn on the effect of vertebroplasty on mortality of patients with osteoporosis. Moreover no data on the medical treatments, including antiosteoporotic drugs, that the patients received during follow-up are available in these analyses.

\section{CONCLUSION}

In our daily practice we are facing patients with painful osteoporotic VFs, and our objectives are, beyond pain relief, to prevent the short-term and long-term complications of these fractures. Management of a patient with clinical osteoporotic VF includes use of analgesics, from paracetamol to strong opioids if needed, limited bed rest 
and orthoses. Facet joint injections may help in few cases. Assessment of any cause of secondary osteoporosis and initiation of an antiosteoporotic treatment are mandatory as soon as possible; the first-line therapy (anabolic or antiresorptive) is chosen according to local guidelines on severe osteoporosis, for prevention of imminent risk of refracture and not for any expected analgesic effect. We are aware that these treatments may be not enough in some patients; the presence of unfavourable underlying factors in some patients is the main driver of decision to perform vertebroplasty, rather than a theoretical time since the occurrence of fracture. ${ }^{47}$ Our position is a 'call for action':

- To consider vertebroplasty, after careful assessment of the cause of pain, the fragility of the patient and after comprehensive information of the patient: in a fragile patient with a recent painful VF (proven by MRI) necessitating hospitalisation and bed confinement and failure of appropriate dose of analgesics.

- To put immediately in a research agenda clinical studies to assess the role of baseline mechanical conditions (regional kyphosis angle, sagittal vertebral axis, pelvic incidence) on the results of vertebroplasty, in particular in situations of painful fracture at the thoracolumbar junction, with the rationale of the inherent risk of worsening of height loss of the vertebral body and the subsequent definite sagittal malalignment.

In all cases, a rapid initiation of an antiosteoporotic treatment is mandatory to prevent a new fracture, which is highly predictable in these patients.

Acknowledgements The members of the Scientific Committee of the Groupe de Recherche et d'Information sur les 0stéoporoses (GRIO), and the members of the Bureau of the French Society of Rheumatology (SFR) who gave fruitful comments, and endorsed the manuscript.

Contributors All authors contributed equally to this paper.

Funding The authors have not declared a specific grant for this research from any funding agency in the public, commercial or not-for-profit sectors.

Competing interests None declared.

Patient consent for publication Not required.

Provenance and peer review Not commissioned; externally peer reviewed.

Open access This is an open access article distributed in accordance with the Creative Commons Attribution Non Commercial (CC BY-NC 4.0) license, which permits others to distribute, remix, adapt, build upon this work non-commercially, and license their derivative works on different terms, provided the original work is properly cited, appropriate credit is given, any changes made indicated, and the use is non-commercial. See: http://creativecommons.org/licenses/by-nc/4.0/.

ORCID iD

Christian Roux http://orcid.org/0000-0002-5880-2933

\section{REFERENCES}

1 Roux C, Fechtenbaum J, Kolta S, et al. Prospective assessment of thoracic kyphosis in postmenopausal women with osteoporosis. $J$ Bone Miner Res 2010;25:362-8.

2 Zhang J, He X, Fan Y, et al. Risk factors for conservative treatment failure in acute osteoporotic vertebral compression fractures (OVCFs). Arch Osteoporos 2019;14:24.

$3 \mathrm{Kim} \mathrm{H}-\mathrm{J}$, Yi J-M, Cho H-G, et al. Comparative study of the treatment outcomes of osteoporotic compression fractures without neurologic injury using a rigid brace, a soft brace, and no brace: a prospective randomized controlled non-inferiority trial. J Bone Joint Surg Am 2014;96:1959-66.

4 McGirt MJ, Parker SL, Wolinsky J-P, et al. Vertebroplasty and kyphoplasty for the treatment of vertebral compression fractures: an evidenced-based review of the literature. Spine $J$ 2009;9:501-8.

5 Lamy O, Uebelhart B, Aubry-Rozier B. Risks and benefits of percutaneous vertebroplasty or kyphoplasty in the management of osteoporotic vertebral fractures. Osteoporos Int 2014;25:807-19.

6 Buchbinder R, Johnston RV, Rischin KJ, et al. Percutaneous vertebroplasty for osteoporotic vertebral compression fracture. Cochrane Database Syst Rev 2018;4:CD006349.

7 Ebeling PR, Akesson K, Bauer DC, et al. The efficacy and safety of vertebral augmentation: a second ASBMR Task force report. $J$ Bone Miner Res 2019;34:3-21.

8 Long SS, Morrison WB, Parker L. Vertebroplasty and kyphoplasty in the United States: provider distribution and guidance method, 20012010. AJR Am J Roentgenol 2012;199:1358-64.

9 Ong KL, Beall DP, Frohbergh M, et al. Were VCF patients at higher risk of mortality following the 2009 publication of the vertebroplasty "sham" trials? Osteoporos Int 2018;29:375-83.

10 Bousson V, Hamze B, Odri G, et al. Percutaneous vertebral augmentation techniques in osteoporotic and traumatic fractures. Semin Intervent Radiol 2018;35:309-23.

11 Diamond TH, Champion B, Clark WA. Management of acute osteoporotic vertebral fractures: a nonrandomized trial comparing percutaneous vertebroplasty with conservative therapy. Am J Med 2003;114:257-65.

12 Alvarez L, Alcaraz M, Pérez-Higueras A, et al. Percutaneous vertebroplasty: functional improvement in patients with osteoporotic compression fractures. Spine 2006;31:1113-8.

13 Nieuwenhuijse MJ, van Erkel AR, Dijkstra PDS. Percutaneous vertebroplasty for subacute and chronic painful osteoporotic vertebral compression fractures can safely be undertaken in the first year after the onset of symptoms. $J$ Bone Joint Surg $\mathrm{Br}$ 2012;94:815-20.

14 Farrokhi MR, Alibai E, Maghami Z. Randomized controlled trial of percutaneous vertebroplasty versus optimal medical management for the relief of pain and disability in acute osteoporotic vertebral compression fractures. J Neurosurg Spine 2011;14:561-9.

15 Blasco J, Martinez-Ferrer A, Macho J, et al. Effect of vertebroplasty on pain relief, quality of life, and the incidence of new vertebral fractures: a 12-month randomized follow-up, controlled trial. J Bone Miner Res 2012;27:1159-66.

16 Wang B, Guo H, Yuan L, et al. A prospective randomized controlled study comparing the pain relief in patients with osteoporotic vertebral compression fractures with the use of vertebroplasty or facet blocking. Eur Spine J 2016;25:3486-94.

17 Voormolen MHJ, Mali WPTM, Lohle PNM, et al. Percutaneous vertebroplasty compared with optimal pain medication treatment: short-term clinical outcome of patients with subacute or chronic painful osteoporotic vertebral compression fractures. The VERTOS study. AJNR Am J Neuroradiol 2007;28:555-60.

18 Klazen CAH, Lohle PNM, de Vries J, et al. Vertebroplasty versus conservative treatment in acute osteoporotic vertebral compression fractures (Vertos II): an open-label randomised trial. Lancet 2010;376:1085-92.

19 Miller FG, Kallmes DF, Buchbinder R. Vertebroplasty and the placebo response. Radiology 2011;259:621-5.

20 Buchbinder R, Osborne RH, Ebeling PR, et al. A randomized trial of vertebroplasty for painful osteoporotic vertebral fractures. $N$ Engl $J$ Med 2009;361:557-68.

21 Kallmes DF, Comstock BA, Heagerty PJ, et al. A randomized trial of vertebroplasty for osteoporotic spinal fractures. $N$ Engl J Med 2009;361:569-79.

22 Clark W, Bird P, Gonski P, et al. Safety and efficacy of vertebroplasty for acute painful osteoporotic fractures (VAPOUR): a multicentre, randomised, double-blind, placebo-controlled trial. The Lancet 2016;388:1408-16.

23 Firanescu CE, de Vries J, Lodder P, et al. Vertebroplasty versus sham procedure for painful acute osteoporotic vertebral compression fractures (VERTOS IV): randomised sham controlled clinical trial. BMJ 2018;361:k1551.

24 Clark W, Bird P, Diamond T, et al. Cochrane vertebroplasty review misrepresented evidence for vertebroplasty with early intervention in severely affected patients. BMJ Evid Based Med 2020;25:85-89.

25 Diamond T, Clark W, Bird P, et al. Percutaneous vertebroplasty for acute painful osteoporotic vertebral Fractures-Benefits shown in vapour trial masked when pooled with other clinical trials. J Bone Miner Res 2019;34:1182-4.

26 Nieuwenhuijse MJ, Bollen L, van Erkel AR, et al. Optimal intravertebral cement volume in percutaneous vertebroplasty 
for painful osteoporotic vertebral compression fractures. Spine 2012;37:1747-55

27 Yen $\mathrm{CH}$, Teng MMH, Yuan WH, et al. Preventive vertebroplasty for adjacent vertebral bodies: a good solution to reduce adjacent vertebral fracture after percutaneous vertebroplasty. AJNR Am J Neuroradiol 2012;33:826-32.

28 Wang L, Yang H, Shi Y, et al. Sandwich vertebral fracture in the study of adjacent-level fracture after vertebral cement augmentation. Orthopedics 2012;35:e1225-30.

29 Lindsay Ret al. Risk of new vertebral fracture in the year following a fracture. JAMA 2001;285:320-3.

30 Firanescu CE, de Vries J, Lodder P, et al. Percutaneous vertebroplasty is no risk factor for new vertebral fractures and protects against further height loss (VERTOS IV). Cardiovasc Intervent Radiol 2019;42:991-1000.

31 Martinez-Ferrer A, Blasco J, Carrasco JL, et al. Risk factors for the development of vertebral fractures after percutaneous vertebroplasty. J Bone Miner Res 2013;28:1821-9.

32 Han SLet al. Is vertebroplasty a risk factor for subsequent vertebral fracture. meta-analysis of published evidence? Osteoporos Int 2015;26:113-22.

33 Ong KL, Lau E, Kemner JE, et al. Two-Year cost comparison of vertebroplasty and kyphoplasty for the treatment of vertebra compression fractures: are initial surgical costs misleading? Osteoporos Int 2013;24:1437-45.

34 Hopkins TJ, Eggington S, Quinn M, et al. Cost-Effectiveness of balloon kyphoplasty and vertebroplasty versus conservative medica management in the USA. Osteoporos Int 2020;31:2461-71.

35 Fechtenbaum J, Etcheto A, Kolta S, et al. Sagittal balance of the spine in patients with osteoporotic vertebral fractures. Osteoporos Int 2016;27:559-67.

36 Dai J, Yu X, Huang S, et al. Relationship between sagittal spinal alignment and the incidence of vertebral fracture in menopausal women with osteoporosis: a multicenter longitudinal follow-up study. Eur Spine J 2015;24:737-43.

37 Baek S-W, Kim C, Chang $\mathrm{H}$. The relationship between the spinopelvic balance and the incidence of adjacent vertebral fractures following percutaneous vertebroplasty. Osteoporos Int 2015;26:1507-13.

38 Iwata A, Kanayama M, Oha F, et al. Does spinopelvic alignment affect the Union status in thoracolumbar osteoporotic vertebral compression fracture? Eur J Orthop Surg Traumatol 2017;27:87-92.

39 Kao F-C, Huang Y-J, Chiu P-Y, et al. Factors predicting the surgical risk of osteoporotic vertebral compression fractures. J Clin Med 2019;8:501.

40 Klazen CAH, Venmans A, de Vries J, et al. Percutaneous vertebroplasty is not a risk factor for new osteoporotic compression fractures: results from VERTOS II. AJNR Am J Neuroradiol 2010;31:1447-50.

41 Blattert TR, Schnake KJ, Gonschorek O, et al. Nonsurgical and surgical management of osteoporotic vertebral body fractures: recommendations of the spine section of the German Society for orthopaedics and trauma (DGOU). Global Spine J 2018;8:50S-5.

42 Edidin AA, Ong KL, Lau E, et al. Mortality risk for operated and nonoperated vertebral fracture patients in the medicare population. $J$ Bone Miner Res 2011;26:1617-26.

43 McDonald RJ, Achenbach SJ, Atkinson EJ, et al. Mortality in the vertebroplasty population. AJNR Am J Neuroradiol 2011;32:1818-23.

44 Levy H, Seydafkan S, Rice JD, et al. Comparative efficacy of vertebroplasty, kyphoplasty, and medical therapy for vertebra fractures on survival and prevention of recurrent fractures. Endocr Pract 2012;18:499-507.

45 Ong KL, Beall DP, Frohbergh M, et al. Were VCF patients at higher risk of mortality following the 2009 publication of the vertebroplasty "sham" trials? Osteoporos Int 2018;29:375-83.

46 Hinde K, Maingard J, Hirsch JA, et al. Mortality outcomes of vertebral augmentation (vertebroplasty and/or balloon Kyphoplasty) for osteoporotic vertebral compression fractures: a systematic review and meta-analysis. Radiology 2020;295:96-103.

47 Hirsch JA, Beall DP, Chambers MR, et al. Management of vertebral fragility fractures: a clinical care pathway developed by a Multispecialty panel using the RAND/UCLA appropriateness method. Spine J 2018;18:2152-61. 